CRITICAL REVIEWS AND

THEORETICAL ARTICLES 


\title{
TEMPERATURE AS A DEPENDENT VARIABLE IN THE STUDY OF CHOLINERGIC MECHANISMS
}

\author{
STEVEN C. DILSAVER and NORMAN E. ALESSI \\ Department of Psychiatry, Mental Health Research Institute \\ University of Michigan, Michigan, U.S.A. \\ (Final form, July, 1987)
}

\section{Contents}

1. Introduction

2. Principles of Cholinergic Pharmacology

3. Uses of Thermoregulation Strategies in Neurobiological Fesearch

3.1. Neuropharmacology of Antidepressant Withdrawal Phenomena 3.2. The Use of Temperature as a Dependent Variable in Studying Cholinergic 9
Mechanisms in the Neurobiology of Stress

3.3. Use of Temperature as a Depondent Variable to Study the Cholinergic 11 Pharmacology of Lithium

3.4. Temperature as an Fndpoint in Studying the Biology of Electronconvulsive 13 Shock (ECS)

4. Areas for Future Investigation Using Temperature as Dependent Variable 14

4.1. The Pharmacology of Substance of Abuse 14

4.2. Application to Clinical Research 21

5. Conclusions 23

Acknolwedgements $\quad 23$

References $\quad 23$

Abstract

Dilsaver, Steven C. and Norman F. Alessi: Temperature as a Dependent Variable in the Study of Cbolinergic Mechanisms. Prog. Neuro-Psychopharmacol. \& Biol. Psychiat. 1988, 12: 1-32.

1. Change in core temperature over time can be used as a dependent variable when studying the effects of manipulations on neurotransmitter systems. This article focuses on the measurement of core temperature as a strategy for detecting changes in the status of cholinergic systems.

2. Cholinergic neurons participate in the process of thermoregulation and interventions affecting them alter the thermal response to cholinomimetics. For example, chronic treatment with amitriptyline, chronic swim stress and inescapable footshock supersensitize rats to the hypothermic effects of oxotremorine.

3. This is consistent with the hypothesis that the pathophysiologies of tricyclic antidepressant withdrawal phenomena and stress involve supersensitivity of muscarinic mechanisms.

4. Uses of thermoregulation paradigms for investigating the actions of lithium ion, electroconvulsive shock and substances of abuse on muscarinic mechanisms are discussed. Applications to problems in the arena of clinical research are highlighted. 
Keywords: amitriptyline, cholinergic mechanism, lithium, muscarinic mechanisms, oxotremorine

Abbreviations: acetylcholine (Ach), amitriptyline (AMI), desipramine (DMI), dexametbasone suppression test (DST), electroconvulsive shock (ECS), gamma aminobulgric acid (GABA), gigantocellular field (FTG), lithium (Li), muscarinic receptors (mAchRs), oxotremorine (OXO), reticular activating system (RAS), rapid eye movement (REM), tricyclic antidepressant (TCA), tritiated quinuclidinyl ([ $\left.3_{\mathrm{H}}\right]$ QNB)

\section{Introduction}

This article comments on and reviews the use of temperature as a endpoint in the study of cholinergic mechanisms. The cholinergic component of thermoregulation, methods of altering it, and the use of core temperature as a dependent measure in neuropharmacological studies are discussed. Our objective is to emphasize the power of an experimental strategy. The effects of tricyclic antidepressants (TCAs), lithium $\left(\mathrm{Li}^{+}\right)$, antimuscarinic agents, ethanol, opiates, barbiturates, cannabinoids, benzodiazepines, electroshock therapy (EST), and chronic stress on cholinergic systems are described.

Dopaminergic (Eoschi and Launay, 1985; Colboc and Costentin, 1980; Lin et al, 1984), noradrenergic (Clark and Clark, 1980a), serotonergic (Ferguson et al, 1985; Lin et al, 1981; Simpson and Resch, 1985; Yamawaki, et al, 1983), GABAergic (Serraon et al, 1985), peptidergic (Clark and Lipton, 1985), nicotinic (Armitage et al, 1967; Dilsaver et al, 1987c; Horstman, 1984; Marks et al, 1983; Marks and Collins, 1984; Nordberg and Wahlstrom, 1980) and muscarinic (Clark and Clark, 1980; Lomax et al, 1969; Lomax, 1970; Lomax and Jenden, 1966; Meyers and Yaksh, 1968) systems partially regulate core temperature in mammals.

Factors complicate the use of thermoregulation paradigms. Organisms vary in their thermic responses to drugs. Agents producing a decline in temperature in one species cause an increase in another (Lomax et al, 1969). Second, response is dependent on the dose and route of administration. Central microinjection of acetylcholine (Acb) produces thermogenesis in rats and cats (Beckman and Carlisle, 1969) but systemic administration of a muscarinic agonist produces hypothermia (Dilsaver et al, 1987c; Friedman et al, 1969; Jaffe and Sharpless, 1969). Third, experiments are required to determine if the response to a centrally active drug is due to a central effect. For example, systemically infused cholinergic agonists produce hypothermia in rodents. This could be due either to heat loss secondary to peripheral vasodilitation or a central action. 
Experiments described in this article involve the systemic administration of agonists. Assuming that a drug penetrates the blood brain berrier, peripheral injection leads to delivery to all central sites sensitive to it. A response is the summation of all positive and negative effects on a variable. Thus, even if a manipulation produces supersensitivity to a muscarinic agonist, one cannot conclude all muscarinic sites are aupersensitized. Despite this complexity, it is possible to devise experiments which allow one to draw inferences about mechanisms underlying alterations of the thermoregulatory process.

\section{Principles of Cholinergic Pharmacology}

Certain principles facilitate posing problems amenable to solution using thermoregulation paradigms, the use of methods available for manipulating cholinergic systems, and the interpretation of data. These are:

Principle $I$ is "drugs affecting cholinergic systems at least indirectly interact with cbolinergic receptors." Some agents do so directly, e.g., muscarinic receptors (mAchRs) bind muscarinic agonists. However, anticholinesterases indirectly affect mAchR mediated changes by inhibiting the bydrolyais of Ach. This principle is not absolute. Pharmacological manipulations can change neuronal systems through non-apecific ffects on membrane fluidity. For example, Baron and Kloog (1984) reported that the incorporation of certain fatty acids into the cell membrane enhanced the sensitivity of mAchRs. However, the assumption that pharmacological manipulations alter cholinergic systems through actions on receptors is valid in many experimental contexts. One can be reasonably confident of this if the properties of the independent variable used are known. This assumption has heuristic value. When dependent and independent variables bear a lawful relationship to one another, one might ask, "What could occur at the receptor that explains this phenomenon?" This can lead to new experiments to assess whether the independent variable is associated with changes in receptor density or affinity, alterations in second messenger systems, etc. (Dilsaver, 1986f).

Principle II: Wile there are distinct nicotinic receptors (nAchRs) and mAchRs in the periphery, it cannot be assumed that the mammalian brain has true nAchRs (Morley and Kemp, 1981). However, it does bave receptors which bind nicotine (Marks and Collins, 1984; Nordberg et a1, 1985), a-bungarotoxin (Clarke et al, 1985) and neosurugatoxin (Yamada et al, 1985) and wich respond to nicotinic agonists. Some central cholinoceptors may be sensitive to both muscarinic and nicotinic agonists (Morley and Kemp, 1981). 
Some drugs used to study $\mathrm{mAch}$ mediated phenomena have nicotinic effects. Pilocarpine is a classic muscarinic agonist, yet it exerts weak nicotinic effects (Bowman and Rand, 1980). Physostigmine is used to study contributions of muscarinic dysfunction to disturbances of mood (Janowsky et al, 1980), neuroendocrine function (Risch et al, 1981, 1983), and polysomnographic parameters (Sitaram and Gillin, 1980; Sitaram et al, 1979, 1984). However, it diffusely inbibits the hydrolysis of Ach. nAchRs, mAchRs and receptors with joint muscarinic-nicotinic sensitivity are thus activated. Determining the relative nicotinic and muscarinic effects of this drug involves a careful study. Westfall (1973), for instance, reported that Ach inhibited the release of norepinephrine in rat brain slices whereas a nicotinic agonist promoted its release. The simultaneous administration of a calcium chelating agent and Ach resulted in the release of norepinephrine. Ach acts at sites sensitive both to muscarinic and nicotinic agonists but the muscarinic component of its action is calcium dependent.

Principle III: Binding data are adynamic measures which convey nothing about the function of a system. The literature often equates "supersensitivity" to Ach with "up-regulation" or "supersensitive mAchRs." This reflects conceptual error (Dilsaver, 1986f). "Up-regulation" is an increase in the maximum density of mAchRs. "Supersensitivity" is enhanced bebavioral, physiological or biochemical responsiveness to agents. It has to do with function. Supersensitivity can be receptor independent. Lerer and Belmaker (1982) observed increased sensitivity to monoaminergic agonists in the absence of changes in receptor binding parameters. A system can be down-regulated and yet be supersensitive if elements comprising it become more efficient. For example, intracytosolic mechanisms translating agonist-receptor union into functionally relevant events could become more responsive to receptor occupation. Consequently, the interrelationship of receptor binding data and functional measures provides the most complete account of the effects of a manipulation on a neurotransmitter system (Dilsaver, 1986b, $f$ ).

Principle IV: Changes in receptor density or affinity and in the sensitivity of an organism to an agonist acting through that receptor can be dissociated in time. We measure robust enhancement of the hypothermic response to oxotremorine (OxO) in rats after 7-12 days of treatment with amitriptyline (AMI), $10 \mathrm{mg} / \mathrm{kg}$ ip twice daily (Dilsaver et al, 1987c). Rehavi et al (1980) studied the effects of this regime on the binding of tritiated quinuclidinyl benzilate ( $\left[{ }^{3} \mathrm{H}\right]$ QNB) in mouse forebrain. Seven days of treatment did not produce up-regulation but 21 did. Goldman and Erickson (1983) documented a $20 \%$ increase in the density of $\left[{ }^{3} \mathrm{H}\right]$ QNB binding sites 
in cortex after the treatment of rats with AMI, $10 \mathrm{mg} / \mathrm{kg}$ twice daily for 30 days. Nomura et al (1982) reported that desipramine (DMI), $10 \mathrm{mg} / \mathrm{kg}$ twice daily, increased the density of QNB binding sites in rat myocardium and augmented the sensitivity of the myocardium to the negative inotropic effects of Ach. Whether central mechanisms generally acquire increased sensitivity to muscarinic agonists prior to, contemporaneously with or after changes in receptor binding density occurs is not known.

Principle V: The value of using a functional parameter as a means of assessing the effects of interventions on muscarinic mechanians is highlighted by considering the $\mathrm{mAchR}$ subtypes. There are two well-defined mAchR subtypes, designated $\mathrm{m}_{1}$ and $\mathrm{m}_{2}$. These were originally defined by the capacity of the former to specifically bind an antagonist, pirenzipine. Pirenzipine binds weakly to mAchR of the heart and smooth muscle but potently to receptors in the cerebral cortex, hippocampus, sublingual gland and sympathetic ganglia (Birdsall et al, 1984). Ricker and Wescoe (1951) first presented evidence that there may be mAchR subtypes when they demonstrated that gallamine selectively inbibited effects of methacholine on myocardium. The bradycardia produced in anesthetized cats by cholinergic stimulation was inhibited by gallamine whereas the hypotension, sweating, salivation and enhanced gut motility were not. Rathvun and Hamilton (1970) and Brown and Crout (1970) provided similar evidence when they reported that pancuronium exbibited cardioselective antimuscarinic effects. They also estimated that the potency of gallamine was 100 to 1,000 fold greater in the rat and cat myocardium in vivo than in guinee pig ileum. An array of specific $\mathrm{m}_{1}$ and $\mathrm{m}_{2}$ antagonists and agonists are available. However, the pharmacological provocations referred to in this article do not implicate a particular receptor subtype. One cannot administer specific $m_{1}$ and $m_{2}$ agonists and antagonists systemically. These drugs leck lipid solubility and it is necessary to administer them centrally. Pirenzipine, the specific $m_{1}$ antagonist and $M c N-A-343$, a specific $m_{1}$ agonist are also charged molecules. Similarly, Mutschler and Lambrecht (1984) found that the effectiveness of specific $m_{2}$ agonists depends on the quaternization of a ring nitrogen atom--a modification limiting the capacity of these analogs to enter the central nervous system.

One can describe phenomenon hased on the systemic administration of drugs and then devise experiments to determine whether $i t$ is mediated by an $m_{1}$ or $m_{2}$ receptor. Pirenzipine or an $m_{1}$ agonist can be administered centrally should peripheral administration suggest that this would be a rewarding experiment. 
This article focuses on studies involving the systemic administration of muscarinic and nicotinic agonists. This approach can be integrated with biochemical or molecular strategies. For example, $m_{1}$ agonists activate the phosphatidylinositol cycle (Fisher and Bartus, 1985). Supersensitization of a muacarinic system associated with interventions discussed below may involve an effect on this receptor subtype. The physiological studies can suggest biochemical experiments.

\section{Uses of Thermoregulation Strategies in Neurobiological Research}

\subsection{Neuropharmacology of Antidepressant Withdrawal Phenomena}

The discontinuation of TCAs produces symptoms suggesting cholinergic overdrive (Dilsaver et al, 1983a,b, Dilsaver and Greden, 1984c). F1rst, TCAs produce physiological and biochemical evidence of mAchR blockade and bind with specificity to central and peripheral machRs (Atkinson and Landinsky, 1972; Richelson and Dininetz-Romero, 1977; Snyder and Yamamura, 1977). Drugs with these properties produce tolerance and hyperexcitability of cholinergic networks (Jaffe and Sharpless, 1969). AMI increased the density of $\mathrm{mAchR}$ radioligand sites in mouse and rat forebrain (Rehavi et al, 1980; Goldman and Erickson, 1983). Nomura et al, (1982) reported that DMI up-regulated mAchR binding sites in rat myocardium. Classic antimuscarinic drugs (Ehlert et al, 1983) do this.

The withdrawal of TCAs can produce three syndromes which are similar to states produced by anticholinesterases. These are gastrointestinal distress accompanied by anxiety and agitation, movement disorder, and sleep disturbance marked by vivid, terrifying dreams and impairment of sleep continuity. These syndromes respond to central mAchR blockade (Dilsaver et al, 1983a,b). Withdrawal-precipitated cholinergic overdrive has been posited as their cause (Dilsaver and Greden, $1984 \mathrm{C}$ ).

Dilsaver et al (1987c) tested the hypothesis that a TCA can produce cholinergic system supersensitivity by telemetrically measuring temperature in rats ( $n=15$ ) given OXO before and after treatment with AMI. Telemetric measurements were made using the Model VM Mini-Mitter (Mini-Mitter Co, Sun River, OR). This instrument, which is surgically implanted into the peritoneal cavity, emits radio waves at a rate proportional to temperature. An AM radio serves as a receiver. Time to enit a given number of sounds is measured using a digital display stopwatch. This measurement is converted to temperature using a linear regression equation derived 
by measuring the emisgion rate of the thermosensors at three temperatures in a temperature controlled water bath. This instrument can detect a change in temperature of $0.1^{\circ} \mathrm{C}$ and remains functional for at least three months. Procedurea governing Mini-Mitter use are available elsewhere (Tocco-Bradley et al, 1985 ).

The cholinomimetic induced hypotherwia was measured before and after treatment with AMT. OXO challenges were preceded by pretreatment with methylscopolamine nitrate, $1 \mathrm{mg} / \mathrm{kg} i p$, to block peripheral effects of the agonist. Baseline temperature was defined as the average of the pre-and post-methylacopolamine measurements. These did not differ in 31 trials $(p<0.1)$. We measured temperature every 15 minutes. Data were analyzed using an ANOVA with repeated measures and paired t-tests. Figure 1 presents the study design.
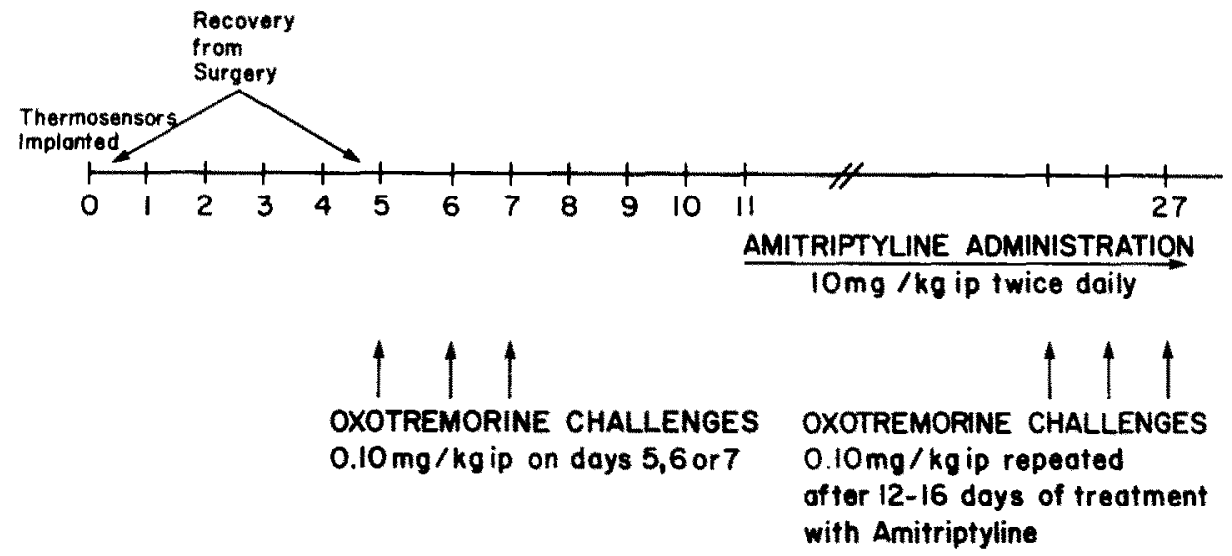

Fig 1. Fifteen animals had Model VM Mini-Mitters implanted. Five days later tbey received challenges, in random order, with oxO (base), $0.05,0.1$ or $0.25 \mathrm{mg} / \mathrm{kg}$ ip. By day 7 all 15 animals had received all doses of oxO. Treatment with AMI, 10 $\mathrm{mg} / \mathrm{kg}$ ip bid ensued. Those rats retaining functional thermosensors were again subject to challenge with $0 \times 0.05,0.10$ and $0.25 \mathrm{mg} / \mathrm{k}_{B}$ ip between days 25 and 27 .

An experiment illustrating the effects of treatment with AMI involved challenge with $0 \times 0,0.125 \mathrm{mg} / \mathrm{kg}$ ip in 11 animals given AMI, $10 \mathrm{mg} / \mathrm{kg}$ twice daily for 26 days plus $20 \mathrm{mg} / \mathrm{kg}$ twice daily for another five days. The maximum decrease $(1.51 \pm 0.19$ 
[SFM]) in temperature relative to baseline produced by this dose did not differ from that elicited by $0 \times 0,2.5 \mathrm{mg} / \mathrm{kg}$ ip in these animals prior to their receiving chronic treatment with AMI $(1.17 \pm 0.11$ [SEM]). The bypothermio response produced by $0 \times 0$, $0.1 \mathrm{mg} / \mathrm{kg}$ ip after $12-14$ days of treatment with AMI approximated that produced by 1 $\mathrm{mg} / \mathrm{kg}$ at haseline. Sensitivity to $0 \times 0,0.05(\mathrm{p}<0.05)$ and $0.25(\mathrm{p}<0.001) \mathrm{mg} / \mathrm{kg}$, also increased significantly. Figure 2 illugtrates the change in responsiveness of the sample $(\mathrm{p}<0.001, \mathrm{~N}=10)$ to $0 \mathrm{XO}, 0.10 \mathrm{mg} / \mathrm{kg}$ after chronic treatment with this AMI schedule. The capacity of AMI to produce supersensitivity to OXO has been confirmed (Dilsaver and Snider, 1987d). Further, multiple injections of oxo does not itself enhance the hypothermic response to subsequent injections (Majchrzak and Dilsaver, 1987; Narks and Collins, 1984).

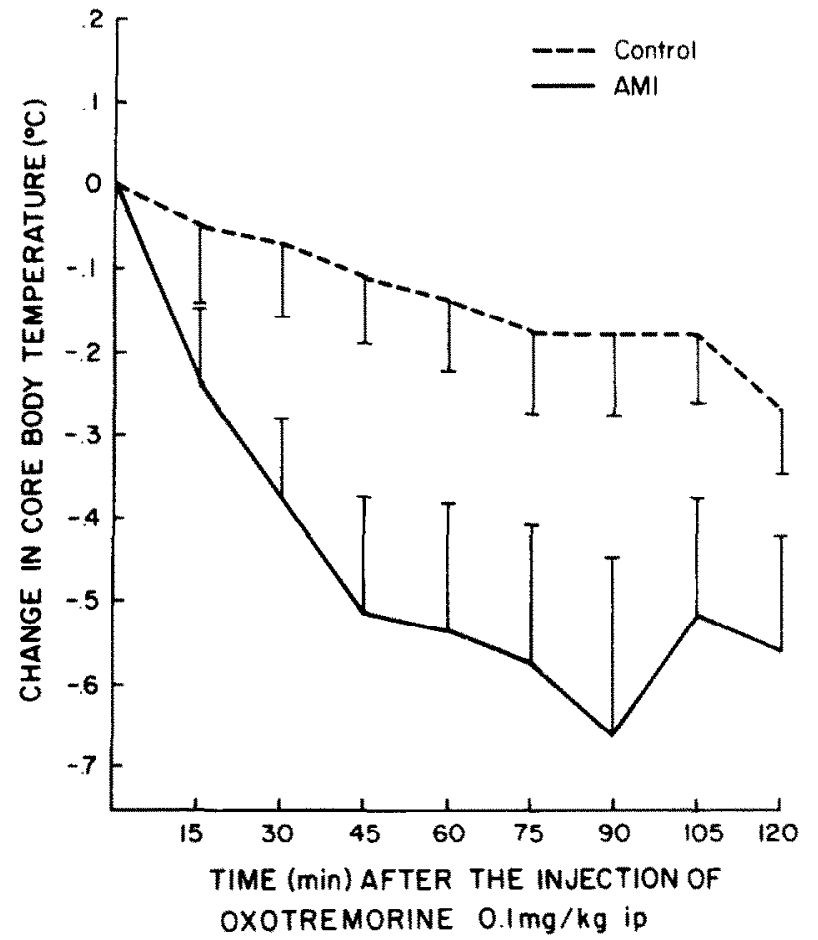

Fig 2. Administration of AMI augmented the hypothermic response to OxO. This illustrates the difference in responsiveness to $0 \times 0$ (base), $0.10 \mathrm{mg} / \mathrm{kg}$ ip before and after 12-16 days of treatment with AMI, $10 \mathrm{mg} / \mathrm{kg}$ ip bid in $10 \mathrm{male}$ rats $(\mathrm{p}<0.02$, ANOVA with repeated measures).

In summary, date support the hypothesis that at least certain TCA withdrawal symptoms are due to cholinergic overdrive. The pathophysiology of affective disorders appears to involve cholinergic system supersensitivity (Dilsaver and Greden, 1984d, D1lsaver, 1986b-e,g; Janowsky et al, 1980). These experiments ironically suggest that AMI produces an abnormality that may characterize some forms 
of affective iliness (Janowsky et al, 1980, 1983; Risch et al, 1981). The use of TCAs and antimuscarinic agents to model the pathophysiology of affective disorders was recently discussed (Dilsaver, 1986b,e,g; Dilsaver and Davidson, 1987 ).

\subsection{The Use of Temperature as a Dependent Variable in Studying Cbolinergic}

Mechanisms in the Neurobiology of Stress

The interrelationship of stress, cholinergic and aminergic physiology and affective disturbance is a developing theme (Dilsaver and Alessi, 1986a, $1987 \mathrm{a}$; Dilsaver, 1986d-f; Janowsky et al, 1983). Dilsaver et al (1986h) hypothesized that chronic atress would produce supersengitivity to $0 \times 0$. OXO-induced hypothermia was measured in rats $(n=5)$. Temperature was measured every 15 min for 120 min, before, during and after chronic swim stress.

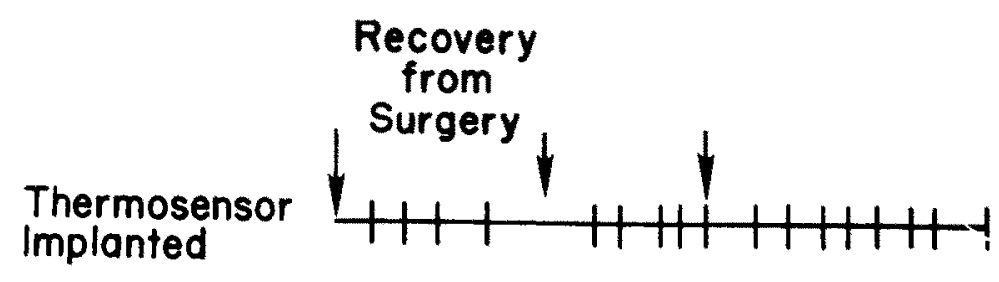

DAYS

STRESS $\begin{aligned} & \text { AM } \\ & \text { PM }\end{aligned}$
0

$\begin{array}{lllll}5 & 10 & 12 & 15 & 18\end{array}$

\section{OXOTREMORINE}

CHALLENGE

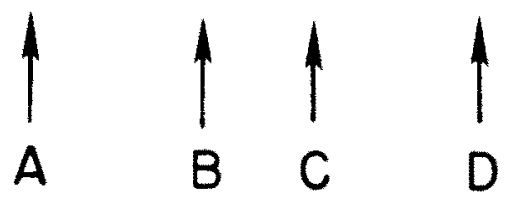

Fig 3. Design of a study probing the effects of chronic swim stress on a cholinergic mechanism involved in the regulation of core temperature. The Model VM Mini-Mitter was implanted into the peritoneal cavity of 5 rats on Day 0 . On Day 5 , the animals received Oxo challenge (A). Over the next 5 days the animals were subjected to swim stress sessions morning and evening. OXO challenge $B$ followed the last stress session on the morning of Day 10 by 4 hours. OxO challenges $C$ and $D$ followed the final stress sessions by 54 and 196 hours respectively. Please see text for further explanation.

The stuay was divided into three phases as depicted in Figure 3 . Phase 1: Mini-Mitters were implanted into five adult, male rats. The first (I) of five oxO challenges marked the end of Phase 1 . This challenge provided a baseline against 
which data from subsequent challenges was evaluated. Phase 2 (stress): This phase started with the first of 10 swim stress sessions the evening following the first oxo challenge and ended with the last stress session. The animals were stressed morning and evening. OXO challenges II and III also occurred during Phase 1. Challenge II followed the fourth atress session by 2 hours. Challenge III followed the tenth and final stress session (which occurred in the morning) by 4 hours. Phase 3 (recovery): During this 8-day period the animals were not stressed. Challenge IV occurred 48 bours after the last stress session. The fifth challenge followed 192 hours after the last stress period.

OXO Challenge. OX0 challenges were conducted between 1100 and 1400 and were preceded by the administration of methylscopolamine nitrate, $1 \mathrm{mg} / \mathrm{kg}$ ip. Baseline temperature was measured $30 \mathrm{~min}$ later. OXO, $1 \mathrm{mg} / \mathrm{kg} \mathrm{ip}$, was then given and temporature recorded every 15 min for 120 min.

Swim Stress. Stress sessions started 5 days after thermosensor implantation. Swim stress (Weiss et al, 1981) was employed. Sessions were held morning and evening. Duration of the sessions and water temperature were adjusted to produce exhaustion since the animals became stronger over the course of the experiment.

Four hours after the last session, the animals exhibited an enhanced hypothermic response relative to baseline ( $p=0.0049$; ANOVA with repeated measures). The supersensitive response was also present 48 hours later $(p=0.01)$, and there was a highly significant phase effect between challenges I, II and III $(p=0.0003)$. However, 8 days after the last session, responsiveness to oxo did not differ from baseline. Figure 4 illustrates the change in body temperature as a function of time during OXO challenges I-IV.

Dilsaver and Alessi (1986a, 1987a) gave chronic inescapable footshock to 13 rats. Core temperature was measured every 10 minutes for 120 minutes after the injection of $0 X 0$. About 24 hours after the fifth stress session, the sample demonstrated enbancement of the hypothermic response to $0 \times 0$ at all 12 time points $(p=0.0002$ sign test). The sample also exhibited an increase in the mean hypothermic response to $0 \times 0$ ( $p<0.01$, paired $t$-test). Seven animals received 9 consecutive days of inescapable footshock. Twenty-four hours later, 6 exhibited significant enhancement of the hypothermic response to oxotremorine at the level of $\alpha<0.05$ and the sample demonstrated a significant increase in the mean hypothermic response ( $\mathrm{p}<$ 0.01 , paired t-test). 


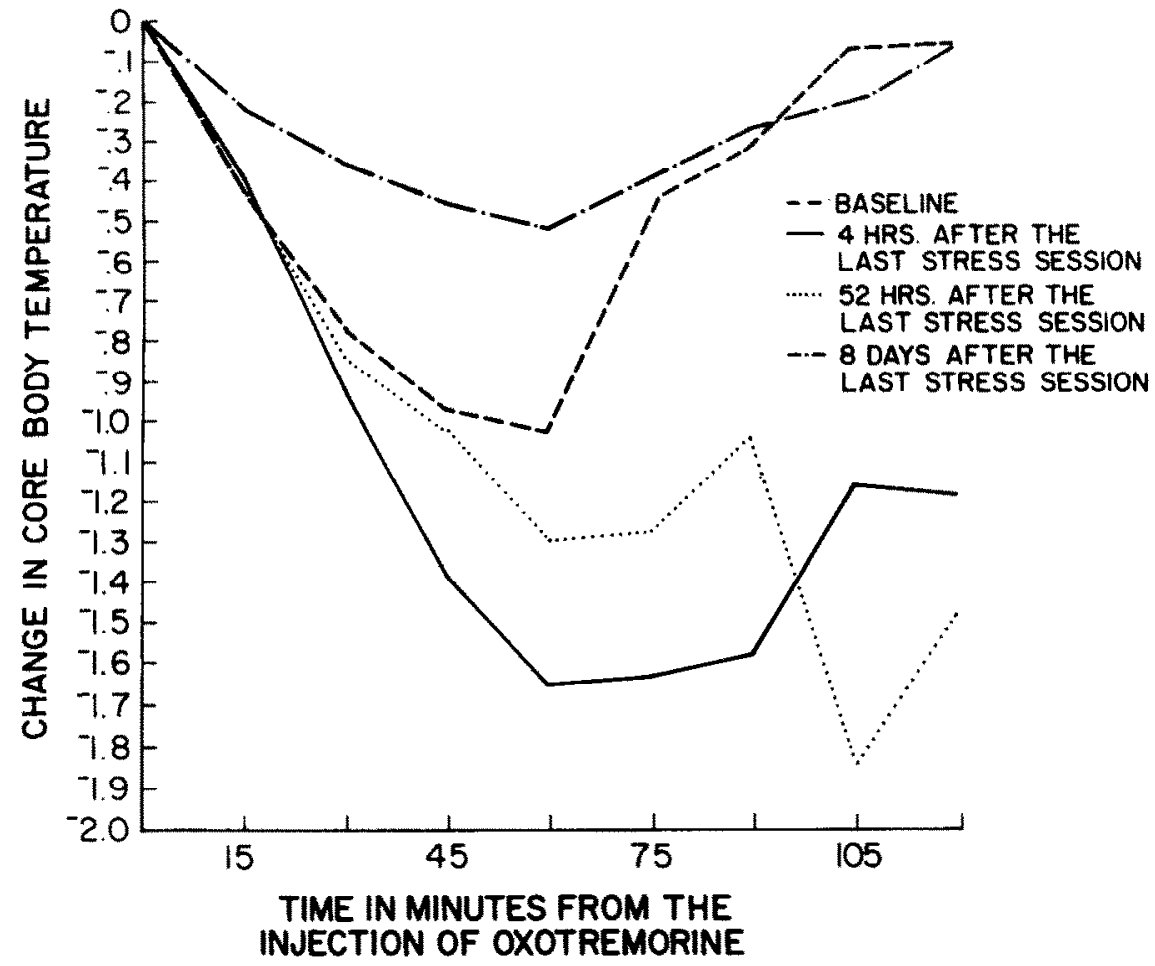

Fig 4. Hypothermic response to $O X O$ (base) $1 \mathrm{mg} / \mathrm{kg}$ ip in a sample (N=5) of rats (A) before, and (B) 4, (C) 52 , and (D) 192 hours after the last of 10 swim stress sessions. A vs $B, p=0.0049$, A vs $C, p=0.019$; A vs $D, n . s$.

In conclusion, chronic forced swim stress and inescapable footshock produced cholinergic system supersensitivity. The findings suggest that chronic atress has the potential to interact with a central muscarinic mechanisms. The utility the thermoregulation peradigms in stress research requires further evaluation. Weiss et al (1981) described effects of uncontrollable stressors on biogenic amine metabolism. Serotonergic, dopaminergic, and noradrenergic agents can also be used to study the effects of stress on aminergic systems (Haggstrom et al, 1984) using core temperature as a dependent measure.

\subsection{Use of Temperature as a Dependent Variable to Study the Cholinergic} Pbarmacology of Lithium

Levy et al (1982) reported thet the $\mathrm{Li}^{+}$prevents the induction of $\mathrm{mAch}$ up-regulation by atropine in vivo. Pestronk and Drachman (1980) found that the $\mathrm{Li}^{+}$reduced the proliferation of extrajunctional aAchRs in denervated skeletal 
muscle. These findings raise the possibility that $\mathrm{Li}^{+}$down-regulates or subsensitizes nicotinic mechanisms. However, Tollefson and Senogles (1982) reported that $\mathrm{Li}^{+}, 1 \mathrm{mEq} / 1$ in vitro, produced a $50 \%$ ( $\left.\mathrm{p}<0.05\right)$ reduction in the affinity of the mAchR and $23 \%$ decrease $(p<0.10)$ in $B_{\max }$ for $\left[{ }^{3} H\right]$ QNB binding in homogenates of human caudate nucleus. They concluded that decreased affinity of [ $\left.{ }^{3} \mathrm{H}\right] \mathrm{QNB}$ for the $\mathrm{mAchR}$ in the presence of the $\mathrm{Li}^{+}$indicates that the latter is a cholinomimetic-like agent. This is based on the assumption that antagonists and agonists bind to different sites of the mAchR receptor. Presumably, binding to the antagonist site interferes with binding to agonist sites. However, agonists and antagonists competitively displace one another. This suggests that they bind to the same site (Ehlert et al, 1983). Thus, a 23\% reduction in $B_{\max }$ can also be interpreted to suggest that $\mathrm{Li}^{+}$produces a down-regulation of mAchRs (Dilsaver, 1984a).

Lerer and Stanley (1985) presented the strongest data against the hypothesis that lithium rendera muscarinic networks subsensitive. These investigators reported that $\mathrm{Li}^{+}$enhanced the hypothermic response to pilocarpine in rats and that it potentiated the capacity of scopolamine to supersensitize and up-regulate muscarinic networks. Hruska et al, (1984) observed that 21 days of treatment with $\mathrm{Li}^{+}$ reduced the density of $\left[{ }^{3} \mathrm{H}\right] \mathrm{QNB}$ binding sites in homogenates of rat cortex, hippocampus and striatum. The mean concentration of $\mathrm{Ii}^{+}$was $0.68 \mathrm{mEq} / \mathrm{I}$ in the unwashed homogenates. Interestingly, rinsing the homogenates eliminated the difference in $B_{\text {max }}$ between treated and untreated samples. The authors concluded that $\mathrm{Li}^{+}$produces an illusion of $\mathrm{mAchR}$ down-regulation. An alternative interpretation is that $\mathrm{Li}^{+}$modifies the physical properties of neurons thereby reducing the density of functional available mAchRs (Dilsaver, $1986 \mathrm{~b}$ ).

Down-regulation is a literal decrease in the density of receptors whereas "decreased density of receptors available for binding" implies that receptor density may be unchanged but that binding is reduced due to transient modifications such as receptor phosphorylation (Burgoyne, 1983) or the alterations of membranes by nucleotides or other biochemical factors (Blosser and Appel, 1980; Sokolovsky et al, 1980).

$\mathrm{Li}^{+}$causes an immediate reduction in the density of mAcbR binding sites when added to an assay medium but its therapeutic effects lag 7 to 10 days. Shou (1980) observed that it may not be possible to judge the efficacy of $\mathrm{Li}^{+}$until a patient is treated for up to two years. This suggests that there are effects of chronic $\mathrm{Ii}^{+}$that cannot he tapped by a "cross sectional" or in vitro analysis. In vivo studies in animals may better approximate realities of the clinical context. Levy 
et al (1982) illustrated this. Lithium aborted up-regulation of the mAchR produced by atropine but without antecedent pharmacologic perturbation no effect of the ion was measurable.

Will $\mathrm{Li}^{+}$prevent AMI induced supersensitization of the muscarinic mechanism involved in producing hypothermia upon cholinomimetic challenge? The date of levy et al (1982) predict that it will, but those of Lerer and Stanley (1985) do not. $\mathrm{Li}^{+}$'s cholinergic effects may be important to its therapeutic actions. The growing body of information implicating disturbances of muscarinic systems in the pathophysiology of affective disorders would be consistent with this. Future research in this area could focus on the effects of $\mathrm{Ii}^{+}$on multiple physiological functions.

\subsection{Temperature as an Endpoint in Studying the Biology of the Electronconvulsive Shock (ECS)}

ECS produces reliable changes in cholinergic physiology. It immediately increases the release of Ach and reduces the concentration of this neurotransmitter in the cerebral cortex of animals (Longoni et al, 1976). Chronic ECS continues to produce these effects (Essman, 1973; Longoni et $\mathrm{al,} \mathrm{1976).} \mathrm{Man} \mathrm{responds} \mathrm{similerly} \mathrm{to} \mathrm{a}$ convulsion. Fink (1966) showed that tetrazol-induced seizures produce elevations in the cerebral spinal fluid (CSF) concentrations of Ach and choline and that ECS produces an antimuscarinic reversible increase in slow wave activity.

Massive release of endogenous agonists (e.g., Ach) or treatment with exogenous agonists produces down-regulation of target receptors (Eblert et al, 1980; Dilsaver, 1986d; Shifrin and Klein, 1980)). Experts agree that oeizures produce mAchR down-regulation. Dashieff et al (1982) observed a 19 to $25 \%$ reduction in the density of QNB binding sites in rat hippocampus following BCS, one treatment/day for four days. Lerer (1984) obaerved that a single ECS treatment did not affect the density of mAchR binding sites in the rat hippocampus or cerebral cortex but that one treatment daily for seven days produced decreases of 13 and $15 \%$ in the density of $\mathrm{mAch}$ radioligend binding sites in these regions, respectively.

Reductions in mAchR density do not necessarily imply a change in function. Means of relating structural and functional statements amplify the mesning of data in each category. Lerer (1984) did this. He measured the effects of ECS on thermoregulation and mAchR binding density in rats given ECS once daily for 7 daya. ECS produced a reduction in the density of mAchR binding aites in the cerebral cortex but not the hippocampus. The maximum cataleptic response to pilocarpine was 
reduced in animals given $\operatorname{ECS}(n=10)$, once daily for 7 days, relative to shem treated animals $(p<0.05)$. Measurement of the effects of ECS on other cholinergically medisted functions, including studies using temperature as a dependent variable are now desirable. The strategy of studying the effects of ECS in animals subject to an agent producing cholinergic system supersensitivity might be useful. One strategy is to determine whether ECS prevents the intensification of the bypothermic response to cholinomimetic challenge which follows chronic treatment with mAchR antagonists (Dilsaver, 1986b).

\section{Areas for Future Investigation Using Temperature as a Dependent Variable}

Previous sections focused on areas in which study has been conducted. We will now deal with areas of theoretical importance.

\subsection{The Pharmacology of Substances of Abuse}

Nonpsychedelic abusable substances frequently activate monoaminergic systems or inhibit cholinergic networks by blocking the $\mathrm{mAch}$ or inhibiting the release of $\mathrm{Ach}$ (Dilsaver, $1987 \mathrm{~h}, i$ ). This section focuses on six categories of abusable agents, antimuscarinic agents, barbiturates, benzodiazepines, cannabinoids, ethanol, and opiates. These drugs have similar effects on cholinergic mechanisms. Antimuscarinic agents block the postsynaptic mAchR and the others inhibit the release of Ach from presynaptic nerve terminals.

Drugs blocking the postsyaaptic mAchR may have antidepressant properties (Dilsave, $1986 \mathrm{~b}, e$ ) and can produce euphoria (Dilsaver, 1987h,i). These agents produce up-regulation (Ehlert et $a 1,1983$ ) and supersenaitivity of cbolinergic mechanisms (Dilsaver et al, 1983b) and their abrupt discontinuation causes symptoms of cholinergic rebound (Dilsaver and Greden, 1984c; Dilsaver et al, 1983a,b, 1984b), escape of plasma cortisol from suppression by dexamethasone (Dilsaver and Greden, 1985) and increased REM density and decreased REM latency (Sitaram et al, 1979). The behavioral, neuroendocrine and sleep EEG findings associated with the withdrawal of antimuscarinic agents suggest cholinergic overdrive (Dilsaver, 1986e; Dilgaver and Davidson, 1987e; Dilsaver and Greden, 1984c; Dilsaver et al, 1983a,b). Agents blocking the release of Ach can also produce euphoria. Cannabinoids, opiates, barbiturates and ethanol all reduce Ach release from nerve terminals in rodents. Depressed mood and affect and somatic symptoms of melancholia often follow the diacontinuation of these drugs--an observation consistent with some form of the cholinergic hypothesis of depression (Dilsaver, 1986b-d,g). 
Table 1 summarizes effects of antimuscarinic agents, cannabinoids, barbiturates, ethanol, and oplates on muscarinic systems. In general, their acute effect is antagonism of muscarinic cholinergic systems and potentiation of the monoaminergic networks whose function is inhibited by cholinergic mechanismo. Cholinergicmonominergic interaction is not necessarily antagonistic but there is evidence that, in addition to the striatum, these syatems exert opposite and counterbalancing effects within the mesolimbic system (Friedhoff and Alpert, 1973; Jaeckle and Dilsaver, 1986).

Figure 5 highlights the interrelationships of cholinergic and monoaminergic systems as they pertain to the effects of abusable drugs.

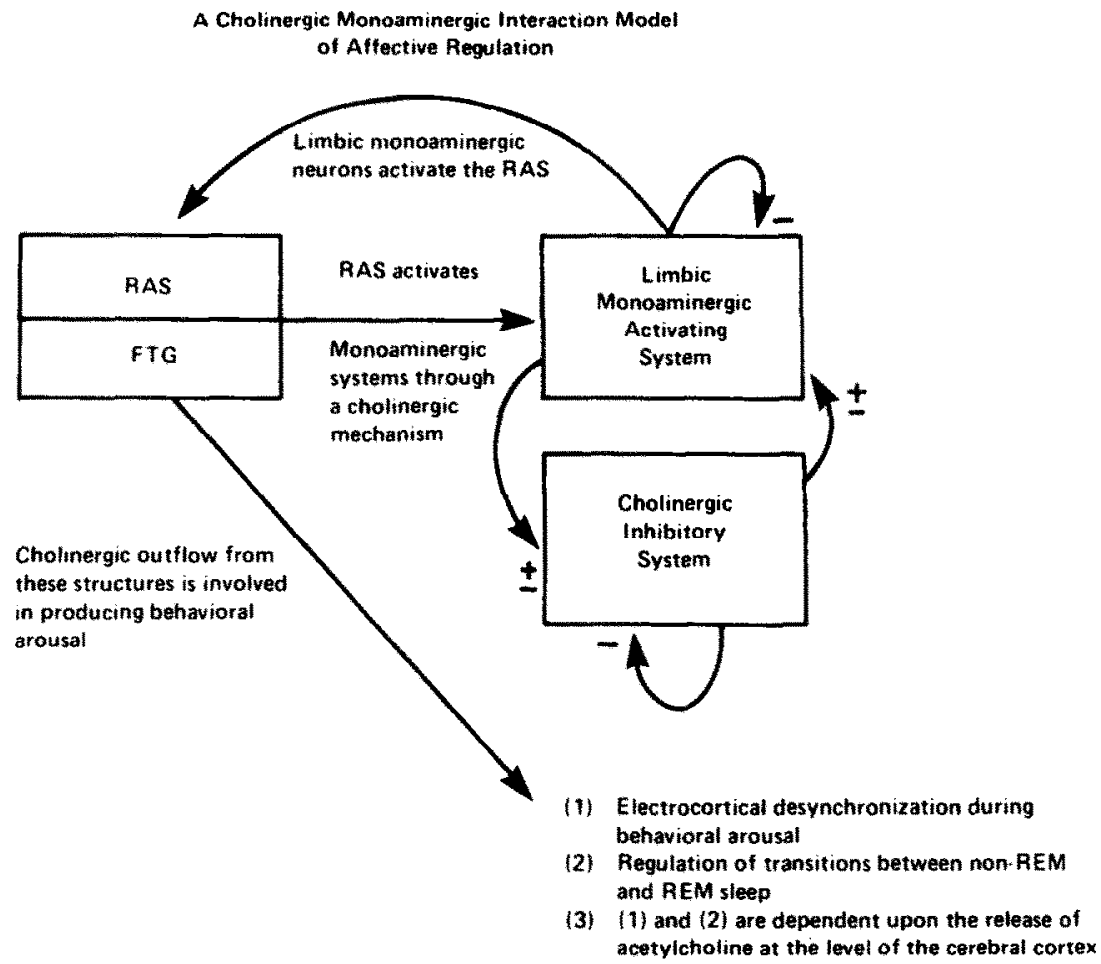

Fig 5. Cholinergic-Monoaminergic Interaction-Theory of affective regulation. The model focuses on mechanisms involved in the regulation of mood and affect, hedonic capacity, psycbomotor function, arousal and sleep. The reticular activating system 

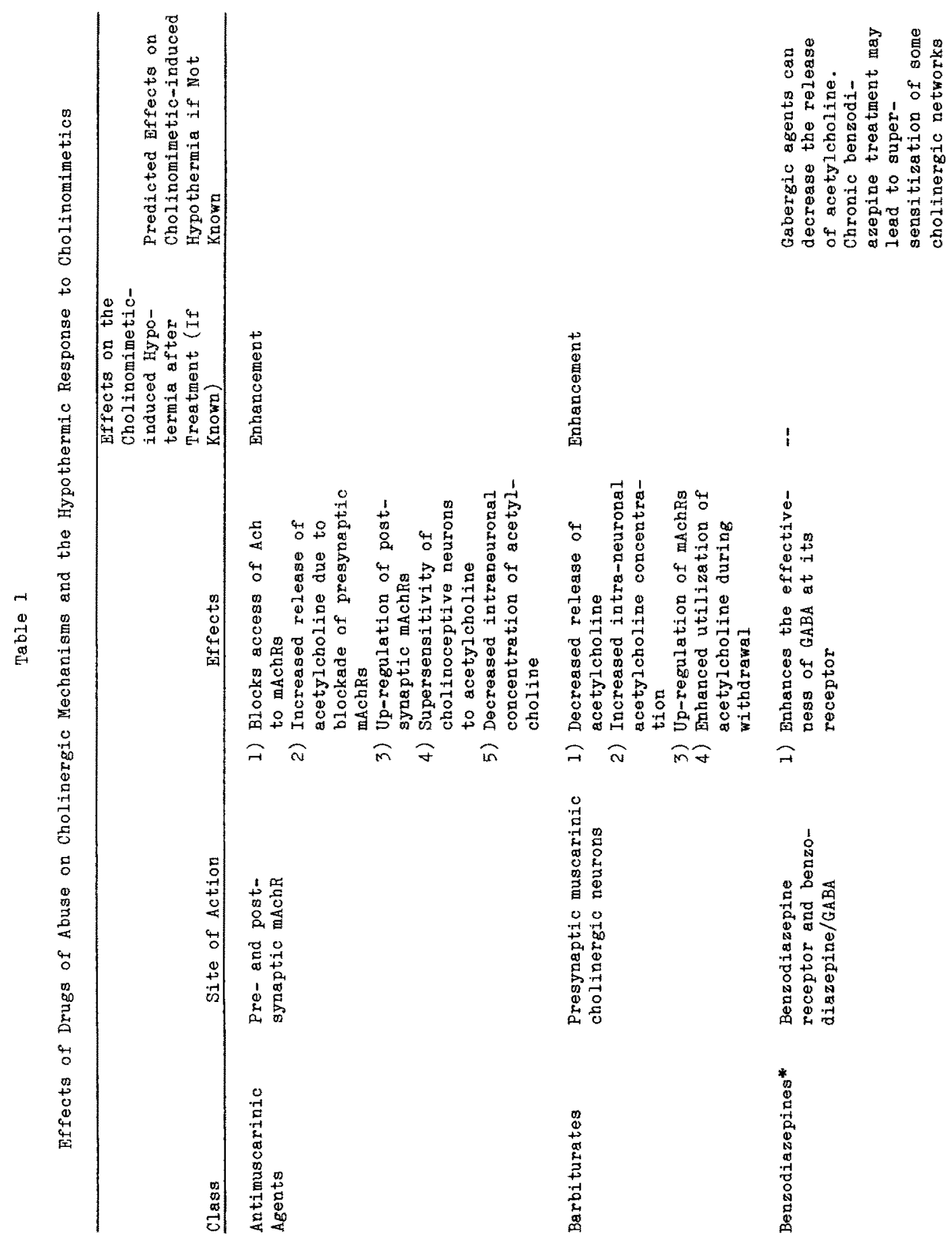

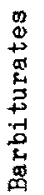

$*$
0
0
0
0
0
0
0
0
0
0
-1
0
0
0
0
0
0
0 


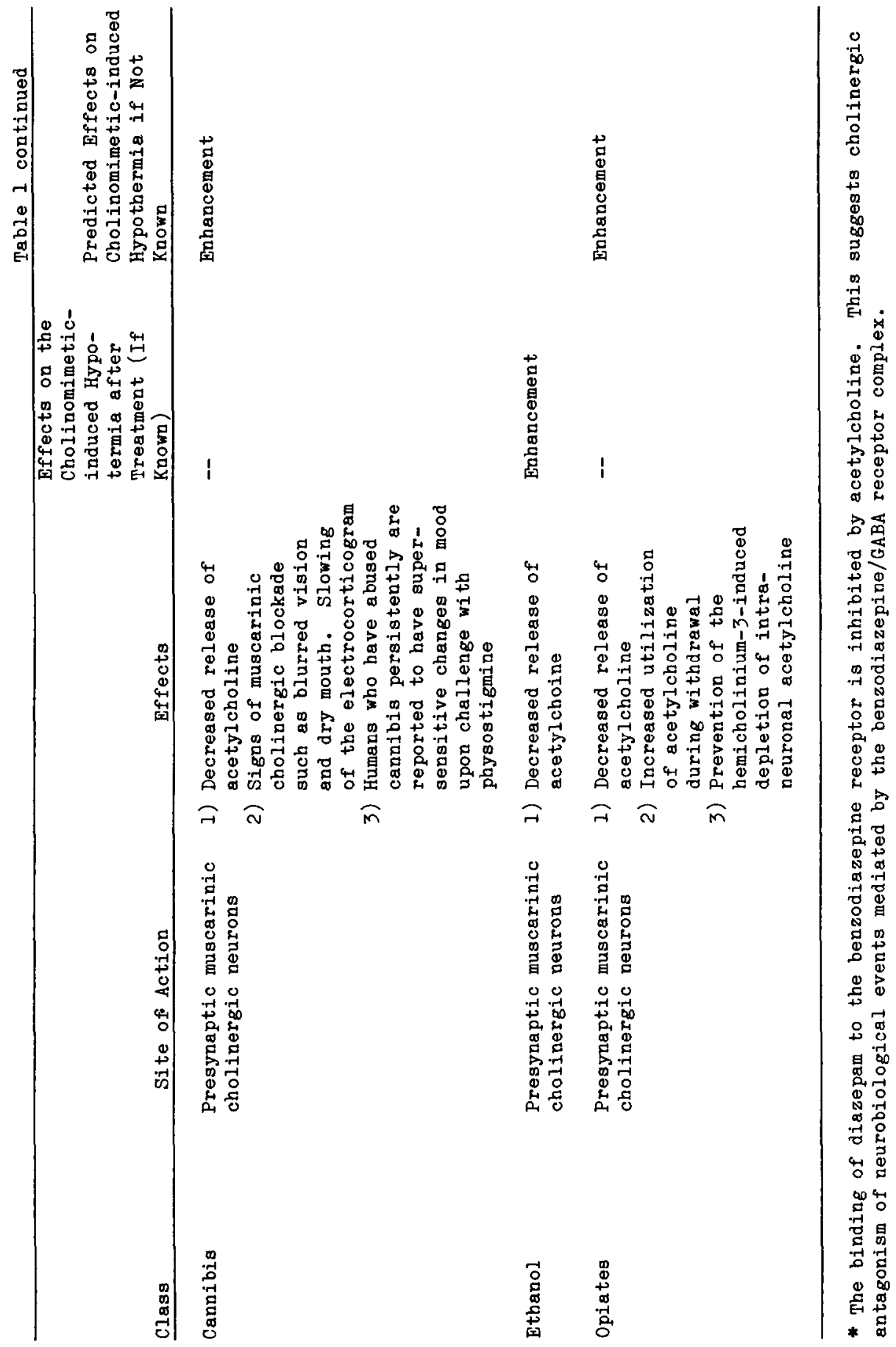


(RAS) interacts with IImbic aminergic nuclei which influence the level of behaviorel arousal. Cholinergic neurons of the gigantocellular-tegmental field (FTG) interact with adrenergic neurons of the locus cereolus to regulate the timing of REM-nonREM trensitions. The RAS and FTG contain cholinergic neurons with terminals at the level of the cerebral cortex. These neurons can affect electrocortical desynchrony by releasing Ach. This occurs during behavioral arousal and transitions to REM sleep. Cholinergic limbic neurons interact with monoaminergic cells to modulate mood, affect, some neuroendocrine functions, psychomotor status and other variables relevant to affective and substance abuse disorders. These systems are auto- and inter-regulated. Thus, the status of monaminergic variables is related to the status of variables describing the cholinergic limbic nuclei and vice-versa.

Cholinergic effects of antimuscarinic agents and drugs blocking the release of Ach may be related to the pathophysiology of drug dependence and tolerance (Dilsaver, 1987h). Tolerance to antimuscarinic agents is associated with mAchR up-regulation and supersensitivity of cholinergic systems (Dilsaver, 1986b). Other aruga can supersensitize cholinergic systems. Marijuana is an example. Cannabinoids produce tachycardia, dry mouth, diminished REM sleep, slowing of the electroencorticogram, short-term memory deficits and other characteristics of mAchR blockade (Dukes, 1980; Jaffe, 1980). They also increase the striatal and amygdalar concentrations of Ach--indication of a decrease in the release of Ach (Yosbimura et al, 1974). At high concentrations, cannabinoids completely block the release of Ach from presynaptic cholinergic neurons at neuromuscular junctions (Kumbarachi and Nastuk, 1980). Cannabinoids also decrease the release of Ach at muscarinic synapses (Layman and Milton, 1971; Revuelta et al, 1979). Assuming sufficient potency, agents with this property will induce up-regulation and supersensitivity of cholinergic systems. Animal studies and clinical reports are consistent with this. El-Yousef et $\mathrm{al}$ (1973) observed that chronic marijuana abusers developed severe depression upon infusion of physostigmine. Further, delta- ${ }^{9}$ tetrabydrocannabinol potentiates the toxicity of this anticholinesterase in rats (Rosenblatt et al, 1972). Dilsaver et al (1984b) observed profound depression in an 18-year-old woman who chronically abused marijuana and who abruptly discontinued thiothixene and benztropine.

Withdrawal symptoms included tearfulness, agitation, tenseness of muscles, behavioral withdrawal, apathy, quietness or fearfulness, psychomotor slowing, sleeplessness for three days, poor self-care, fear of losing ber mind, nausea, vomiting, anorexia and diarrhea. This syadrome responded to atropine sulfate, 1.2 mg every 4 hours, without the occurrence of a noteworthy side-effect. We concluded that cannabis induced cholinergic system supersensitivity and that psychotropic withdrawal triggered a cholinergic overdrive state.

Ethanol is also a potent inhibitor of the release of Ach (Carmichael and Israel, 1975). Treatment with etbanol via addition to water produced a 115 to $124 \%$ increase in the density of QNB binding aites in hippocampal and cortical homogenates 
(Tabakoff et al, 1979). This change was associated with withdrawal seizures during the first 24 hours of abstinence. Smith (1983) administered etbanol, 7\% by volume in drinking water, to mice for 8 days. The synaptosomal fraction from the brains of these animals showed a $128 \%$ increase in specific mAchR radioligand binding. Rabin et al (1980) also showed that ethanol produces an increseed density of QNB binding sites in the cerebrum. Soliman and Gabriel (1985) reported that a single injection of ethanol resulted in a decrease $(p<0.05)$ in choline acetyltransferase activity in multiple regions of mouse brain but that repeated injection ( $3 \mathrm{~g} / \mathrm{kg}$ once daily) did not generally result in a further increase in the activity of this enzyme after the second or third day. Tolerance also developed to the hypothermic effects of ethanol after the third injection. These investigators proposed that tolerance to ethanol involves activation of a cholinergic mechanism. Majchazak and Dilsaver (1987) recently used the Model VM Mini-Mitter to document that chronic treatment with ethanol (14\% v:v) produces supersensitivity to the hypothermic effects of oxO, $0.25 \mathrm{mg} / \mathrm{kg} \mathrm{ip}$, in rats $(\mathrm{n}=8, \mathrm{p}<0.0001$, ANOVA with repeated measures). The results of their study is illustrated in Figure 6 . The administration of $0 x 0,0.25 \mathrm{mg} / \mathrm{kg} \mathrm{ip}$ every other day for 10 days failed to alter the thermic response to this muscarinic agonist. This strongly suggests that ethanol supersensitizes a muscarinic cholinergic mechanism which is involved in the regulation of core temperature.

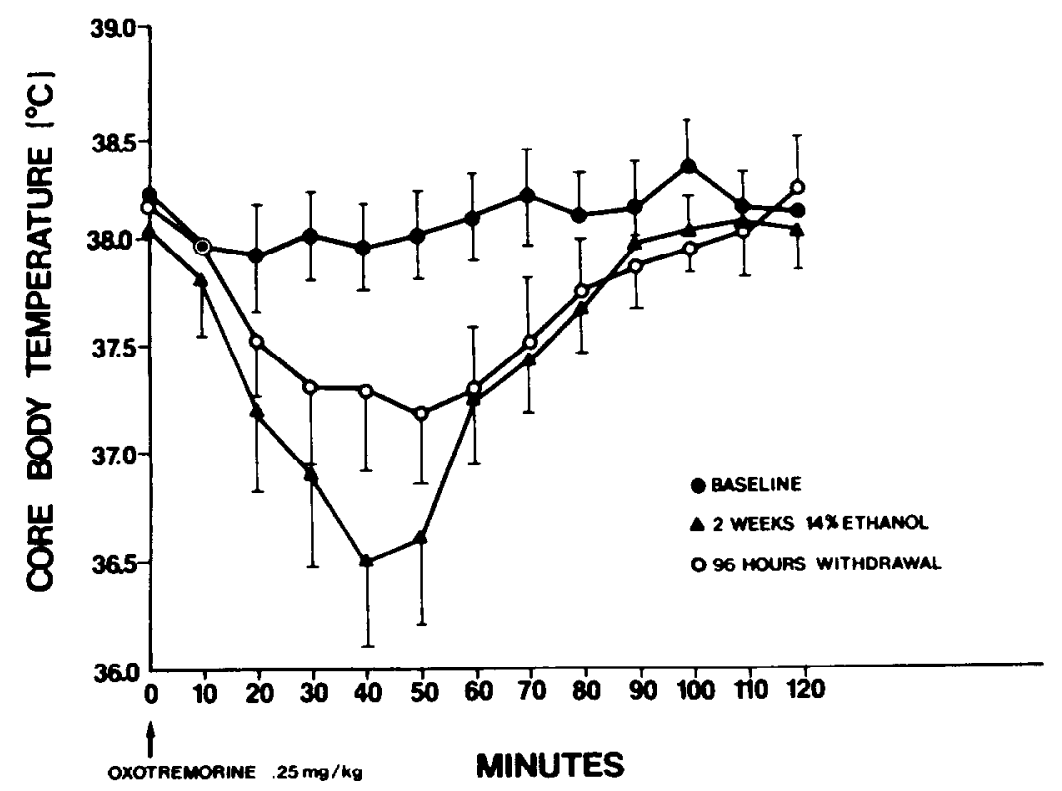

Fig 6. Eight adult male Sprague-Dawley rats were challenged with $0 \times 0,0.25 \mathrm{mg} / \mathrm{kg}$ before and after treatment with $14 \%$ ethanol ( $v: v$ ) in drinking water. The change in hypothermic reaponse was aignificant at the 0.0001 level (ANOVA with repeated measures). Ninety-six (96) hours after the discontinuation the animals remained supersensitive $(p<0.02)$. 
Pentobarbitol inhibits the release of Ach (Domino and Wilson, 1972, 1973; Schuberth et $a 1,1969$ ) and the withdrawal of a barbiturate increases the utilization and turnover of Ach (Wablatröm and Norberg, 1979). The latter finding indicates enhanced release of Ach during the withdrawal phase. Wahlström (1978) reported that chronic treatment with barbital produced supersensitivity to choline as inferred from the threshold to induction of seizures. Wahlström and Ekwall (1976) showed that animals chronically treated with barbital demonstrate supersensitivity to the hypothermic effects of pilocarpine. Finally, the chronic administration of barbiturates produced up-regulation of mAchRs in the brains of rats (Nordberg and Wahlström, 1979, 1980). Thus, acute treatment with a barbiturate decreases the release of Ach and chronic administration produces up-regulation and supersensitivity of muscarinic mechanisms.

Opiate agonista also inhibit the release of Ach and could aupersenaitize muscarinic systems (Jhamandas et al, 1970; Paton, 1957). The withdrawal of opiates produces signs and symptoms of cholinergic overdrive states (Dilsaver, $1987 \mathrm{~h}$ ). These include nausea, vomiting, anorexia, diarrhea, myalgeas, insomnia, anxiety, coryza, irritability, cephalgia, dizzyness, tachycardia and hypertension. The withdrawal of TCAs or the intravenous injection of physostigmine or arecoline also produce these (Dilsaver, 1983b; Dilsaver and Greden, 1984c). While opiate withdrawal states are too complex to be explained by a cholinergic mechanism alone, it is conceivable that they involve a cholinergic component.

The effects of benzodiazepines on the mAchR mediated fall in core temperature is of theoretical intereat. Benzodiazepines facilitate the binding of yaninobutyric acid (GABA) to its receptor. There are reports that GABA inhibits the release of Ach (Agardh et al, 1985; Giotti et al, 1985; Schultz and Lund, 1983; Wood and Richard, 1982). Injection of the GABA agonist, muscimol, into the septum decreases the turnover of Ach in the hippocampus (Wood et al, 1979). This implies a decreased release of Ach. The regulation of Ach release by GABA in this region is consistent with the neuroanatomical finding that there is a large population of GABAergic interneurons in the septum (Fonnum and Walaas, 1978). Chronic treatment with benzodiazepines might inhibit the release of Ach from presynaptic terminals and thereby denervate cholinergic neurons. The result should be enhancement of the hypothermic response to muscarinic agonists.

Table I lists the sites at which the six groups of abusable agents discussed above act upon muscarinic systems, the effects of their actions at these loci, and the known or predicted impact of chronic treatment with these drugs upon the cholinomimetic induced fall in core temperature. Note that all six classes can 
produce euphoria or have anxiolytic properties. Cholinergic mechanisms were long ago accorded a role in the pathophysiology of mood disorders (Dilsaver, 1986b-e) and more recently were proposed to be involved in the neurobiology of stress (Dilsaver and Alessi, 1987a; Janowsky et 81,1983 ) and anxiety (Dilsaver, 1986f). Direct blockade of posteynaptic mAchRs or inhibition of the release of Ach might be linked to the euphoriagenic and anxiolytic properties of these agents. However, their effect is to up-regulate and supersensitize muscarinic systems. This raises important questions. First, "Do these compensatory changes in cholinergic networks limit the long-term clinical utility of certain anxiolytics?: Secondly, "Does tolerance and addiction to the therapeutic effects of benzodiazepines involve up-regulation and supersensitivity of cholinergic systems?" One might speculate that anxiolytics and antidepressants devoid of a capacity to up-regulate and supersensitize cholinergic systems would, ceteris paribus, be less apt to produce tolerance and physiological addiction.

In conclusion, several substances of abuse inhibit cholinergic systems by blocking the postsyneptic $\mathrm{mAchR}$ or decreasing the release of Ach. These result in the supersensitization of cholinergic systems. The significance of these factors to the biology of dependence, tolerance and withdrawal phenomena is unknown. Physiological endpoints sensitive to cholinergic agonists, such as temperature, may be useful in studying the actions of some of these agents on cholinergic systems.

\subsection{Applications to Clinical Research}

Body temperature can be measured telemetrically in man. Dabbs and Neuman (1978) used a pulse-modulated radio frequency transmitter mounted to the ear to measure tempcrature against the ear drum. The device has the appearance of a hearing aid. The system was comprised of a temperature sensor and transmitter, a device for mounting these, a receiver and an instrument for decoding the signal recorded. The transmitter consisted of a temperature sensor, multivibrator and radio frequency oscillator. The resigtance of the sensor is regulated by temperature and determines the oscillatory frequency of a multivibrator. Pulse frequency is proportional to temperature. A thermistor can also be used to manually measure rectal temperature at specified intervals (Avery et $a 1,1982$ ) or a rectal probe attached to a computer system can automatically record temperature (Henane et al, 1973).

REM latency, duration of the first REM period, elevated REM density, and core temperature retain their typical relationship during depressive episodes (Avery et al, 1982; Czeisler et al, 1980; Schultz and Lund, 1983). Treatment with scopolamine 
followed by an abrupt withdrawal produced changes in REM sleep simulating those marking primary depression (Sitaram et al, 1979). These findings suggest an interesting question. "Does treatment with an antimuscarinic agent produce simultaneous phase advance of the REM and sleep-temperature cycles in normal man?" If so, a particular neurotransmitter mechanism is implicated in the pathophysiology of both REM sleep and the altered temperature activity cycle in the affective disorders.

Thermoregulation strategies can also be used to study the effects of agents on cholinoceptive neurons. For example, evidence that chronic treatment with TCAs supersensitizes muscarinic mechanisms could be strengthened by demonstrating that the withdrawal of these agents produces a atropine sensitive decrease in a body temperature over time. This might occur if withdrawal of a TCA produces cholinergic overdrive at the critical thermoregulatory sites. Challenge with a cholinergic agonist before and after chronic treatment with a TCA would be a more powerful means of demonstrating supersensitization of the pertinent neurons. Establishing that TCAs supersensitize cholinoreceptive neurons using this strategy would be consistent with reports that the withdrawal of TCAs produces an increased frequency in positive dexamethasone suppression test (DST) results $(p=0.03$ ) and an increase in the absolute concentration of plssma cortisol ( $p<0.0033$ ) post-dexamethasone challenge (Dilsaver and Greden, 1984e, 1985) and REM rebound (Dunleavy et al, 1972).

Effects of $\mathrm{Li}^{+}$on cholinergic physiology can also be studied using a thermoregulation paradigm. One atrategy would be to measure the thermal response to a cholinergic agent before withdrawal of $\mathrm{Li}^{+}$in euthymic patients and again a few weeks after the last dose, provided patients remain in remission. Both consistentiy increased or decreased sensitivity to the muscarinic agonist during lithium prophylaxis would be of interest.

Responsiveness of core temperature to cholinergic drugs might provide a simple means of testing the hypothesis that subjects with certain types of depressive disorders have supersensitive cholinergic systems. Rapidly-cycling patients are ideal for this study. According to existing theory, drug-free patients who rapidly-cycle should exhibit greater changes in body temperature in response to cholinergic challenge during the depressed phase than euthymic or manic phases (Dilsaver and Greden, 1984d).

The questions proposed here for clinical study using a thermoregulation paradigm all allow patients to be their own controls. Using subjects as their own controls 
tends to minimize variance at a fixed sample size and the number of subjects required to obtain meaningful results.

Use of cholinergic agents in human subjects is warranted and feasible. Human Use Committees have approved the use of arecoline (Sitaram et al, 1979) and physostigmine (Janowsky et al, 1980, 1983; Risch et al, 1981, 1983). Thus, the thermoregulation atudies proposed are possible.

\section{Conclusions}

Messurement of core temperature provides a means of quantifying effects of pharmacologicel manipulations on cholinergic systems. The process of thermoregulation involves central and peripheral mechanisms but studies can be designed which justify the conclusion that central mechanisms generate a given result. Many behavioral, physiological and biochemical measures are useful as dependent variables when studying central functions in health or disease. Abnormalities of these variables can result from changes in the density of a particular type of receptor or alteration of the sensitivity of neurons to transmitter (Dilsaver, 1986b). Pathology can be modeled by pharmacologically inducing changes in the physiology of neurotransmitter networks (Dilsaver, $1986 \mathrm{~b}, e, f$ ). Mood and affect (Dilsaver, 1986b), psychomotor function (Greden and Carroll, 1981), hedonic capacity (Dilsaver, 1986b), pupillary physiology (Soli et al, 1980), sleep architecture (Sitaram and Gillin, 1980), neuroendocrine variables (Carrol1, 1982; Dilsaver, 1986b,e,f), power spectral analysis (Duffy et al, 1979), ratea of cyclic GMP generation (Kanba and Ricbelson, 1984), or phospholipid turnover (Berridge and Irvine, 1984; Fisher and Agranoff, 1985; Fisher and Bartus, 1985), and core temperature are all useful dependent variables in psychopharmacological study (Dilaver, 1986b). However, none is measured with greater ease and economy of expense than core temperature. Perhaps it is underutilized:

\section{Acknowledgements}

This work was supported in part by a Physician Scientist Career Development Award to SCD (Muscarinic Receptor Abnormalities in Affective Illness), Grant \#MHO055302 and NIH 2507RRO5383-25

\section{References}

AGARDH, E., YEH, H.H., HEIRMAN, R. and PIERO, G. (1985) r-aminobutynic acid-mediate inhibition at cholinergic synapse formed by cultured retinal neurons. Brain Res. 330: 323-324. 
ARMITAGE, A.K., HALI, G.H., and MILTON, A. (1967) Effects of nicotine injected into and infused ugh the cerebral ventricles of the cat. Ann. N.Y. Acad. Sci. 80: $27-39$.

ATKINSON, J. and LANDINSKY, H. (1972) The quantitative study of the anticholinergic action of several tricyclic antidepressants on the rat isolated fundal strip. Br. J. Pharmeol. 45: 519-524.

AVERY, D.D., WTLDSCHIOTZ, G., and RAFAELSEN, M.V. (1982) REM latency and temperature in affective disorder before and after treatment. Biol. Psychiatry $17: 463-470$.

BARON, B. and KLOOG, Y. (1984) Fatty acid incorporation increases affinity of muscarinic cholinergic receptors for agonists. Biochem. Biophys. Acta i: 342-350.

BECKMAN, A.L. and CARLISLE, H.J. (1969) Effect of intrahypothalamic infusion of acetyloholine on behavioral and phyaiological thermoreguiation in the rat. Nature (Iondon) 221: 561-562.

BERRIDGE, M.J. and IRVTNE, R.F. (1984) Inosital trisphosphate, a novel second messenger in cellular signal transduction. Nature 312: 315-321.

BTRDSALL, N.J.M., HULME, E.C., and STOCKTON, J.M. (1984) Muscarinic receptor heterogeneity. Trends in Pharmacol. Science, Suppl: 4-8.

BLOSSER, J.C. and APPEL, S.H. (1980) Regulation of acetylcholine receptor by cyclic AMP. J. Biol. Chem. 255: 1235-1238.

BOSCHI, G. and LAUNAY, N. (1985) Differential effects of neuroleptic and serotonergic drugs on ampbetamine-induced hypothermin in mice. Neuropharmacol. 24: $117-122$.

BOWMAN, W.C. and RAND, M.J. (1980) Textbook of Pharmacology, Blackwell Scientific Publications, Oxford, pp. 18-25.

BROWN, B.R. and CROUT, J.R. (1970) The sympathomimetic effects of gallamine on the beart. J. Pharmacol. Expt. Ther. 172: 260-273.

BURGOYNE, R.D. (1983) Regulation of the muscarinio acetylcholine receptor: Effects of phosphorylating conditions on agonist and antagonist binding. J. Neurochem. 40: $24-33 I$.

CARMICHAEL, F.J. and ISRAEL, J. (1975) Effects of ethanol on neurotransmitter release by rat brain cortical slices. J. Pharmacol. Expt. Ther. 193: 824-834.

CARROLI, B.J. (1982) The dexamethasone suppression test for melancholia. Br J Psychiatry 111:659-674.

CLARK, W.G. and CLARK, Y.L. (1980a) Changes in body temperature after the administration of adrenergic and serotonergio agente and related drugs inoluding antidepressants. Neuroscience Biobehav. Rev. 4: 281-375.

CLARK, W.G. and CLARK. Y.L. (1980) Changes in body temperature after the administration of scetylcholine, bistamine, prostaglandins and related agents. Neuroscience and Behav. Rev. 4: $175-240$.

CLARK, W.S, and LIPTON, J.M. (1985) Changes in body temperature after administration of amino acids, peptides, dopamine, neuroleptics and related agents: II, Neuroscience and Behav. Rev. 9: 299-371. 
CLARKE, P.B.S., SCHWARTZ, R.D., PAUL, S.M., PERT C.B., and PERT, A. (1985) Nicotinic binding in rat brain: Autoradiograpbic Comparison of $\left[{ }_{\mathrm{H}}\right.$ ]Nicotine, and $[125 I]-\alpha$-Bungarotoxin. J. Neuroscience 5:1307-1315.

COLBOC, 0. and COSTENTIN, J. (1980) Evidence for thermoregulatory dopaminergic receptors located in the prepticus medialis nucleus of the rat hypothalamus. J. Pharm. Pharmacol. 32: 624-629.

CZEISLER, C.A., ZIMMERMAN, J.C., RODA, J.M., MOORE-EDE, M.C., and WEITZMAN, E.D. (1980) Timing of RFM sleep is coupled with circadian rbythm of body temperature in man. Sleep 2: 329-346.

DABBS, J.M. and NEUMAN, M.R. (1978) Telemetry of buman cerebral temperature. Psychopharmacology 15: 599-603.

DASHEIFF, R.M., SAVAGE, D.D., and MCNAMARA, J.0. (1982) Seizures in hippocampal down-regulate formation. Brain Res. 235: 327-334.

DILSAVER, S.C. (1984a) Lithium's effects on muscarinic receptor binding parameters: A possible relationship to its therapeutic efficacy. Biol. Psychiatry 19: 1551-1565.

DILSAVER, S.C. (1986b) Pharmacologic induction of cholinergic system up-regulation and supersensitivity in affective disorders research. J. Clin. Psychopharmacol. 6: $65-72$.

DILSAVER, S.C. (1986c) Pathophysiology of cholinoceptor "supersensitivity" in affective disorders. Biol. Psychiatry 21: 813-829.

DILSAVER S.C. (1986d) Cholinergic-monoamineric interaction in the pathophysiology of affective disorders. International Clin. Psychopharmacology 1: 181-198.

DILSAVER, S.C. (1986e) Cholinergic mechanisms in depression. Brain Res. Rev. 11: $285-316$.

DILSAVER, S.C. (1986f) Cholinergic and monoaminergic systems, depression and panic. Biol. Psychiatry 21: 571-572.

DILSAVER, S.C. (1986g) Cholinergic mechanisms in affective disorders: Future direction for investigation. Acta Psychiatrica Scandinavica 74: 312-337.

DILSAVER, S.C. (1987h) The pathophysiologies of substance abuse and affective disorders: An integrative model? J. Clin. Psychopharmacol.

DILSAVER, S.C. (1987i) Antimuscarinic agents as substances of abuse. J Clin Psychopharmacol, in press.

DILSAVER, S.C. and ALESSI, N.E. (1986a) Inescapable footshock produces supersensitivity of a cholinergic system. Presented at the Annual Meeting of the American College of Psychopharmacology, Washington, D.C., December 8-12.

DILSAVER, S.C. and ALESSI, N.E. (1987a) Chronic inescapable footshock produces cholinergic system supersensitivity. Biol Psychiatry 22: 914-918.

DILSAVER, S.C. and DAVIDSON, R. (1987e) Cholinergic effects of desipramine and amoxapine: Assessment using thermoregulation paradigm. Progress in Neuro/Psychopharm. and Biol. Psych., in press. 
DILSAVER, S.C. and GREDEN, J.F. (1984C) Antidepressant withdrawal phenomena. Biol. Psychiatry 19: 237-256.

DILSAVER, S.C. and GREDEN, J.F. (1984d) Antidepressant withdrawal-induced activation: Mechanisms and theoretical significance. Brain Res. Rev. 7: $29-42$.

DILSAVER, S.C. and GREDEN, J.F. (1984e) Antidepressant withdrawal and hypothalamic-pituitary-adrenal regulation. Presented at the $137 \mathrm{tb}$ Annual Meeting of the American Psychiatric Association, Los Angeles, California, May 5-11. NR 26.

DILSAVER, S.C. and GREDEN, J.F. (1985) The effects of antidepressant withdrawal on the DST status of endogenously depressed patients. Psychiatry Res. 14: 111-122.

DILSAVER, S.C. and SNIDER, R.M. (1987a) Amitriptyline produces dose-dependent supersensitization of a central muscarinic mechanism. J. Clin. Psychopharmacol., in press.

DILSAVER, S.C., FEINBERG, M., and GREDEN, J.F. (1983a) Antidepressant withdrawal symptoms treated with anticholinergic agents. Am. J. Psychiatry 140: 249-251.

DILSAVER, S.C., KRONFOL, Z., SACKALLARES, J.C., and GREDEN, J.F. (1983b) Antidepressant withdrawal syndromes: Evidence supporting the cholinergic overdrive hypothesis. J. Clin. Psychopharmacol. 3: 157-164.

DILSAVER, S.C., LECKRONE, J.G., and GREDEN, J.F. (1984b) An anticholinesterase-like syndrome precipitated by psychotropic withdrawal in a chronic abuser of marijuana. Psychosomatics 8: 632-634.

DILSAVER, S.C., MAJCHRZAK, M.J., and ALESSI, N.E. (1987c) Chronic treatment with amitriptyline produces supersensitivity to nicotine. Biol. Psychiat., in press.

DILSAVER, S.C., SNIDER, R.M., and ALESSI, N.E. (1986h) Stress produces central cholinergic system supersensitivity. Biol. Psychiatry 21: 1093-1096.

DOMINO, E.F. and WILSON, A.E. (1972) Psychotropic drug influences on brain acetylcholine utilization. Psychopharmacology 184: 291-298.

DOMINO, E.F. and WILSON, A.E. (1973) Effect of narcotic analgesic agonists and antagonists on rat brain acetylcholine. J. Pharmacol. Expt. Therap. 184: 18-32.

DUFFY, F.H., BURCHFIELD, J.L., and LOMBROSO, C.T. (1979) Brain electrical activity mapping (BEAM): A method for extending the clinical utility of $\mathrm{EEG}$ and evoked potential data. Ann. Neurol. $\underline{5}: 309-332$.

DUKES, M.N.G. (1980) Social drugs. Meyler's Side Effects of Drugs, M.N.G. Dukes (Ed.), Amsterdam, Excepta Medica, pp. 51-54.

DUNLEAVY, D.L.F., BREZINOVA, V., OSWALD, I., ET AL. (1972) Changes during weeks in effects of tricyclic drugs on the human sleeping brain. Br. J. Psychiatry, $120: 663-672$.

EHLERT, F.J., ROESKE, W.R., and YAMAMURA, H.I. (1983) The nature of muscarinic binding. In: Handbook of Psychopharmacology, L.L. Iversen, S.D. Iversen, and S.H. Snyder (Eds.), Vol. 17. Plenum, New York.

EHLERT, F.J., KUKKA, N., and FAIRHURST, A.S. (1980) Altered [3H]quinuclidinyl benzilate binding in the striatum of rats following chronic cholinesterase inhibition with diisopropylfluorophosphonate. Molec. Pharmacol. 17: 29-30. 
EL-YOUSEF, M.K., JANOWSKY, D.S., DAVIS, J.M., and ROSENBLATT, J.E. (1973) Induction of severe depression by physostigmine in marijuana intoxicated individuals. $\mathrm{Br}$. J. Addict. 68: 321-325.

ESSMAN, W.B. (1973) Neurochemistry of Cerebral Electroshock. John Wiley, New York.

FERGUSON, A.V., TRESNER, S.L., COOPER, K.E., and VEALE, W.I.C. (1985)

Neurotransmitter effects on body temperature are modified with increasing age. Physiol. Behav. 34: 977-987.

FINK, M.D. (1966) Cholinergic aspects of convulsive therapy. J. Nerv. Ment. Dis. 142: $475-489$.

FISHER, S.K. and AGRANOFF, B.W. (1985) The biochemical basis and functional significance of enhanced phosphatidate and phosphainositide turnover. In: Phospholipids in Nervous Tissues, J. Eichberg (Ed.). John Wiley, New York.

FISHER, S.K. and BARTUS, R.T. (1985) Regional differences in the coupling of muscarinic receptors to inositol phospholipid hydrolysis in guinea pig brain. $\mathrm{J}$. Neuro. Chem. 45: 1085-1095.

FONNUM, F. and WALAAS, I. (1978) The effect of intrahippocampal kainic acid injections and surgical lesions on neurotransmitters in hippocampus and septum. J. Neurochem. 31: 1173-1181.

FRIEDHOFF, A.J. and ALPERT, J. (1973) A dopaminergic-cholinergic mechanism in the production of psychotic symptoms. Biol. Psychiatry 6: 165-169.

FRIEDMAN, M.J., JAFFE, J.H., and SHARPLESS, S.K. (1969) Central nervous system supersensitivity to pilocarpine after withdrawal of chronically administered scopolamine. J. Fharmacol. Exper. Ther. 167: 45-55.

GIOTTI, A., LUZZI, S., MAGGI, C.A., SPAGNESI, S., and ZILLETTI, L. (1985) Modulatory activity of $\mathrm{GABA}_{\mathrm{b}}$ receptors on cholinergic tone in guinea-pig distal colon. Br. J. Pharmcol. 84: 883-895.

GOLDMAN, M.E. and ERICKSON, C.K. (1983) Effects of acute and chronic administration of antidepressant drugs in the central cholinergic nervous system: Comparison with anticholinergic drugs. Neuropharmacol. 22: 1285-1292.

GREDEN, J.F. and CARROLL, B.J. (1981) Psychomotor function and affective disorders. Am. J. Psychiatry 138: 1441-1448.

HAGGSTROM, J.E., SJOQUIST, B., ECKERNAS, S.A., INGUAST, A. and GUNNE, L.M. (1984) Discreet regional distribution of biochemical markers for the dopamine, noradreneline, serotonin, GABA, and acetylcholine systems in the monkey brain (Cebus Apella) Effects of stress. Acta Physiologica Scand. Suppl. 534: 1-27.

HENANE, R., BUGUET, A., ROUSEEL, B., BITTEL, J. (1973) Variations in evaporation and body temperature during sleep in man. J. Applied Physiol., 42:50-55.

HORSTMAN, M. (1984) The influence of mecamylamine on tolerance development to nicotine hypothermia in rats. Pharm. Pharmacol. 36: 770-771.

HRUSKA, R.F., LUDMER, Z.M., PERT, A., and BONNEY, W.E. (1984) Effects of lithium on $\left[{ }^{3} \mathrm{H}\right] \mathrm{C}(-)$ quinuclidinyl benzilate $\left(\left[{ }^{3} \mathrm{H}\right](-)\right.$ QNB) binding to rat brain muscarinic cholinergic receptors. J. Neurosci. Res. 11: 171-177. 
JAECKLE, R. and DILSAVER, S.C. (1986) Covariation of depressive symptoms, Parkinsonism and post-dexamethasone cortisol levels in affective illness. Acta Psychiatrica Scand. 74: 68-72.

JAFFE, J.H. (1980) Drug addiction and drug abuse. In: The Pharmacological Basis of Therapeutics ed. 6, A.G. Goodman, L.S. Goodman, and A. Gilman (Eds.), p. 537. MacMillan, New York.

JAFFE, J.H. and SHARPLESS, S.K. (1969) Pharmacologic denervation supergensitivity in the central nervous system. Research Publications Association Research in Nervous and Mental Disease 46: 226-24l.

JANOWSKY, D.S., RISCH, S.C., HUEY, L., JUDD, L.L., and ROUSCH, J. (1983) Central physostigmine-induced cardiovascular and behavioral changes. Toward an acetylcholine hypothesis of stress. Psychopharmacol. Bull. 19: 675-682.

JANOWSKY, D.S., RISCH, S.C., PARKER, D., HUEY, L., and JUDD, L.L. (1980) Increased vulnerability to cholinergic stimulation in affect disorder patients. Psychopharmacol. Bull. 16(4): 29-31.

JHAMANDAS, K., TINSLEY, C., and PHILLIS J.W. (19'/0) Ef'fects of morphine and its antagonists on release of cerebral cortical acetylcholine. Nature 228: 176-177.

KANBA, S. and RICHELSON, E. (1984) Antimuscarinic effects of lithium. New Engl. J. Med. 310: 989-990.

KUMBARACHT, M.N. and NASTUK, W.L. (1980) Effect of ¿ $^{9}$-tetrahydrocannabinol on excitable membranes and neuromuscular transmission. Molec. Pharmacol. 17: 344-345.

IAYMAN, J.M. and MILTON, A.S. (1971) Some actions of $\Delta \mathbf{b}^{\prime}$-tetrabydrocannabinol and cannabinoids at cholinergic functions. Brit. J. Pharmacol. 41: 379P-380P.

LERER, B. (1984) Electroconvulsive shock and neurotransmitter receptors: Implications for the mechanism of action of electroconvulsive therapy. Biol. Psychiatry 19: 361-383.

LERER, B. and BELMAKER, R.H. (1982) Receptors and the mechanism of action of ECT. Biol. Psychiatry 17: 497-511.

LERER, B. and STANLEY, M. (1985) Effect of chronic lithium ion on cholinergically mediated responses and $\left[3_{H}\right]$ QNB binding in rat brain. Brain Res. 344:211-219.

LEVY, A., ZOHAR, J., and BELMAKER, R.H. (1982) The effect of chronic lithium treatment in rat brain muscarinic receptor regulation. Neuropharmacol. 21: 1199-1201.

LIN, M.T., CHANDRA, A., KO, W.C., and CHEN, Y.M. (1981) Serotonergic mechanisms of clonidine-induced hypothermia in rats. Neuropharmacology 20: 15-21.

LIN, M.T., SHIAN, L.R., and LEU, S.Y. (1984) Clonidine-induced hypothermia: possible involvement of cholinergic and serotonergic mechanisms. Naunyn-Schmiedeben Arch. Pharmacol. 326: 124-128.

LomaX, P. (1970) Urugs and body temperature. Ann. Rev. Neurobiol. 12: 1-43.

LOMAX, P. and JENDEN, D.J. (1966) Hypothermia following systematic and intracerebral injection of oxotremorine in the rat. Neuropharmacology 5: 353-359. 
LOMAX, P., FOSTER, K.F., and KIRKPATRICK, W.E. (1969) Cholinergic and adrenergic interactions in the thermoregulatory centers of the rat. Brain Res. 15: 431-438.

LONGONI, R., MULAS, A., and NOVAK, B.0. (1976) Effect of aingle and repeated electroshock applications on brain acetylcholine levels in the rat. Neuropharmacol. 15: 283-286.

MAJCHAZAK, M. and DILSAVER, S.C. (1987) Ethanol induces supersensitivity to a muscarinic aonist. Psychopharmacology, submitted.

MARKS, M.J. and COLLINS, A.C. (1984) Tolerance, cross-tolerance, and receptors after chronic nicotine or oxotremorine. Pharmacol. Biochem. Behav. 22: 283-291.

MARKS, M.J., BURCH, J.B., and COLLINS, A.C. (1983) Effects of chronic nicotine on tolerance development and nicotinic receptors. J. Pharmacol. Expt. Ther. 226: 817-825.

MEYERS, R.D. and YAKSH, T.L. (1968) Feeding and temperature responses in the unrestrained rat after injections of cholinergic and aminergic substances. Physiol. Behav. 3: 917-928.

MORLEY, B.J, and KEMP, G.E. (1981) Characterization of a putative nicotinic acetylcholine receptgor in mammalian brain. Brain Res. Rev. 3: 8I-104.

MUTSCHLER, E. and LAMBRECHT, G. (1984) Selective muscarinic agonists and antagonists in functional tests. Trends in Pharmacol. Science Suppl: 39-44.

NOMURA, Y. KAJIYAMA, H., and OKAI, K. (1982) Influence of repeated administration of dysmethylimipramine on $B$-adrenergic and muscariniccholinergic receptors and $45 \mathrm{Ca}^{+}$binding to sarcoplasmic reticulum in the rat heart. J. Pharmacol. Exp. Ther. 223: 834-840.

NORDBERG, A. and WAHLSTROM, G. (1980) Increased number of muscarinic binding sites in brain following barbiturate treatment in rat. Life Science 26: 231-237.

NORDBERG, A. and WAHLSTROM, G. (1979) Regional biosynthesis of acetylcholine in brain following forced oral barbitone treatment to rats. J. Neurochem. 32 : 371-378.

NORDBERG, A., WAHLSTROM, G., ARNELO, U., and LARSSON, C. (1985) Effect of long-term nicotine treatment on $\left[3_{\mathrm{H}}\right]$ nicotine binding sites in the rats brain. Neurosci. Lttrs. 59: $27-276$.

PATON, W.D.M. (1957) The action of morphine and related substances on contraction and on acetylcholine output of coaxially stimulated guinea pig ileium. Brit. J. Pharmacol. 125: 119-127.

PESTRONK, A. and DRACHMAN, D.B. (1980) Lithium reduces the number of acetylcholine receptors in skeletal muscle. Science 210: 342 .

RABIN, R.A., WOLFE, B.B., DIBNER, M.D., ZHNISER, N.R., MELCHJOR, C., and MOLINOFF, P.B. (1980) Effects of ethanol administration and withdrawal on neurotransmitter receptor systems in 157 mice. J. Pharmacol. Exp. Ther. 213: 491-496.

RATHVUN, F.J. and HAMILTON, J.T. (1970) Effect of gallamine on cholinergic receptors. Can. Anaesth. Soc. J. 17: 574-589. 
REHAVI, M., RAMOT, O., YAVETZ, B.M, and SOKOLOUSKY, M. (1980) Amitriptyline: Long-term treatment elevates $\alpha$-adrenergic and muscarinic receptor binding in mouse brain. Brain Res. 194: 443-453.

REVUELTA, A.V., CHENEY, D.L., WOOD, P.L., and COSTA, E. (1979) GABAergic mediation in the inhibition of hippocampal acetylcholine turnover rate elicited by $\Delta^{9}$-tetrahydrocannabinol. Neuropharmacology 18: $525,530$.

RICHELSON, E. and DININETZ-ROMERO, S. (1977) Blockade by psychotropic drugs of the muscarinic acetylcholine receptor in cultured nerve cells. Biol. Psychiatry 1?: $771-785$.

RIKER, W.F. and WESCOE, W.C. (1951) The pharmacology and flaxedil, with observations on certain analogs. Ann. N.Y. Acad. Sci. 54: 373-392.

RISCH, S.C., COHEN, P.M., JANOWKSY, D.S., KALIN, N.H., SITARAM, N., GILLIN, J.C. and MURPHY, D.S. (1981) Physostigmine induction of depressive symptomatology in normal human subjects. J. Psychiat. Research 4 : 89-94.

RISCH, S.C., JANOWSKY, D.S., and GILLIN, J. (1983) Muscarinic supersensitivity of anterior pituitary $A C T H$ and $B$-endorphin release in major depressive illness. Peptides 4 : 789-792.

ROSENBLATT, J.E., JANOWSKY, D.S., and DAVIS, J.M. (1972) The augmentation of physostigmine toxicity in the rat by $\Delta^{9}$-tetrahydrocannabinoid. Res. Comm. Chem. Pathol. Pharmacol. 3: 479-481.

SCHUBERTH, J., SPARF, B., and SONDWALL, A. (1969) A technique for the study of acetylcholine turnover in mouse brain in vivo. J. Neurochem. 16: 695-700.

SCHULTZ, H. and LUND, R. (1983) Sleep onset REM episodes are associated with circadian parameters of body temperature: a study in depressives and normal subjects. Biol. Psychiatry 18: 1411-1426.

SERRAON, J.S., MINANSE, F.J., SANEIBRIAN, M., and DUAN, J.A. (1985) Involvement bicuclline-insensitive receptors in the bypothermic effect of GABA and its agonists. Gen. Pharmacol. 16: 505-508.

SHIFRIN, G.S. and KLEIN, W.L. (1980) Regulation of muscarinic acetylcholine receptor concentration in cloned neuroblastoma cells. J. Neurochem. 34: 993-999.

SHOU, M. (1980) Lithium Treatment of Manic-Depressive Iliness. Basil, S. Karger.

SIMPSON, C.W. and RESCH, G.E. (1985) Ach and 5HT stimulated thermogenesis at different core temperatures in the He-Cold hypothermic hamster. Brain Bull. Res. 15: $123-127$.

SITARAM, N. and GILLIN, J.C. (1980) Development and use of pharmacological probes of the CNS in man: Evidence of cholinergic abnormality in primary affective illness. Biol. Psychiatry 15: 925-955.

SITARAM, N, GILLIN, J.C., and BUNNEY, W.E. (1984) Cholinergic and Catecholaninergic Receptor Sensitivity in Affective Tllness. R.M. Post, Williams and Wilkens, Baltimore, Maryland.

SITARAM, N., MOORE, A.M., and GILLIN, J.C. (1979) Scopolamine-induced muscarinic supersensitivity in normal man: Changes in sleep. Psychiatry Res. I: 9-16. 
SMITH, T.L. (1983) Influence of chronic ethanol consumption of muscarinic cholinergic receptors and their linkage to phospholipid metabolism in mouse synaptosomes. Neuropharmacol. 22: 661 663.

SNYDER, S.H. and YAMAMURA, H.L. (1977) Antidepressants and the muscarinic acetylcholine receptor. Arch. Gen. Psychiatry 34: 236-239.

SOKOLOVSKY, M., GURWITZ, D., and GALRON, R. (1980) Muscarinic receptor binding in mouse brain: Regulation of guanine nucleotides. Biochem. Biophys. Res. Commun. 94: $487-482$.

SOLI, N.E., KARLSEN, R.L., OPSAHL, M., and FONNUM, N.E. (1980) Correlation between acetylcholinesterase activity in guinea pig iris and pupillary functions: A biochemical and pupillographic study. J. Neurochem. 35: 723-728.

SOLIMAN, K.F.A. and GABRIEL N.N. (1985) Brain cholinergic involvement in the rapid development of tolerance to the hypothermic action of ethanol. Gen. Pbarmac. 16: $137-140$.

TABAKOFF, B., MUROZ-MARCU, M., and FIELDS, J.Z. (1979) Chronic ethenol feeding produces an incrase in muscarinic cholinergic receptors in mouse brain. Life Science 25: 2173-2180.

TOCCO-BRADLEY, R., KLOGER, M.J., and KOFFMAN, C.A. (1985) Effect of age on fever and acute phase response of rats to endotoxin and Salmonella typhimurium. Infection and Immunity 47: 106-11.

TOLLEFSON, G.D. and SENOGLES, S.E. (1982) A cholinergic role in the mechanism of lithium in mania. Biol. Psychiatry 18: 467-479.

WAHLSTROM, G. (1978) Estimation of brain sensitivity to the convulsive effects of choline and changes induced by chronic barbital treatments in the rat. Eur. J. Pharmacol. 51: 219-227.

WAHLSTROM, G. and EKWALL, T. (1976) Tolerance to hexobarbital and supersensitivity to pilocarpine after chronic barbital treatments in the rat. Eur. J. Pharmacol. 38: $123-129$.

WAHLSTROM, G. and NORBERG, A. (1979) Sensitivity to an active synaptosomal uptake of choline in the abstinence after chronic barbital treatments. Acta Physiologica Scand. Suppl 473: 65-203.

WESTFALL, T.C. (1973) Effect of acetylcholine on the release of $[3 \mathrm{H}]$ norepinephrine by nicotine and potassium chloride from rat brain slices. In; Frontiers of Catecholamine Research, E. Usdin and S.H. Snyder (Eds.), pp 617 618, Pergamon Press, New York.

WEISS, J.M., GOODMAN, P.A., LOSITO, B.G., CORRIGAN, S., CHARNEY, J.M., and BAILEY, W.H. (1981) Behavioral depression produced by an uncontrollable stressor: Relationsbip to norepinephrine, dopamine and serotonin levels in various regions of rat brain. Brain Res. Rev. 3: 167-205.

WOOD, P.L., CHENEY, D.L., and COSTA, E. (1979) An investigation of whether septal $\gamma$-aminobutyic acid containing interneurons are involved in the reduction in the turnover rate of acetylcholine elicited by substance $P$ and $B$-endorphin in the hippocampus. Neuroscience $\underline{4}$ : 1479-1484. 
WOOD, P.L. and RICHARD, J. (1982) Gabergic regulation of the substantia innominata-cortical cholinergic pathway. Neuropharmacol. 21: 969-972.

YAMADA, S., ISOGAI, M., KAGAWA, Y., TAKAYANAGI, N., HAYASHI, E., TSUJI, K., and KOSUGE, T. (1985) Brain nicotinic acetylcholine receptors. Molecular Pharmacol. 28: 120 .

YAMAWAKI, S., LAI, H., and HORITA, A. (1983) Dopaminergic and serotonergic mechanisms of thermoregulation: Modation of thermal effects of apomorphine and dopamine. J. Pharmacol. Exp. Ther. 227: 383-389.

YOSHIMURA, H., FUJIWARA, M., and UEKI, S. (1974) Biochemical correlates in mouse-killing behavior of the rat: Brain acetylcholine and acteylcholinesterase

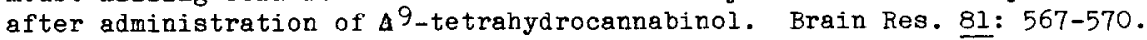

Inquiries and reprints requests should be addressed to:

Dr. Steven C. Dilsaver

Department of Psychiatry

Division of Neuroscience

Ohio State University College of Medicine

Ohio State University

473 West 12th Ave.

Columbus, Ohio 43201-1228

U.S.A. 